\title{
Emissions of carbon tetrachloride from Europe
}

\author{
Francesco Graziosi $^{1,2}$, Jgor Arduini ${ }^{1,2,3}$, Paolo Bonasoni ${ }^{3}$, Francesco Furlani ${ }^{1,2}$, Umberto Giostra ${ }^{1,2}$, \\ Alistair J. Manning ${ }^{4}$, Archie McCulloch ${ }^{5}$, Simon O'Doherty ${ }^{5}$, Peter G. Simmonds ${ }^{5}$, Stefan Reimann ${ }^{6}$, \\ Martin K. Vollmer ${ }^{6}$, and Michela Maione ${ }^{1,2,3}$ \\ ${ }^{1}$ Department of Pure and Applied Sciences, University of Urbino, 61029 Urbino, Italy \\ ${ }^{2}$ National Interuniversity Consortium for Physics of the Atmosphere and Hydrosphere (CINFAI), 00178 Rome, Italy \\ ${ }^{3}$ Institute of Atmospheric Sciences and Climate, National Research Council, 40129 Bologna, Italy \\ ${ }^{4}$ Hadley Centre, Met Office, Exeter, EX1 3PB, UK \\ ${ }^{5}$ School of Chemistry, University of Bristol, Bristol, BS8 1TH, UK \\ ${ }^{6}$ Laboratory for Air Pollution and Environmental Technology, Swiss Federal Laboratories for Materials Science and \\ Technology (Empa), 8600 Dübendorf, Switzerland
}

Correspondence to: Michela Maione (michela.maione@uniurb.it)

Received: 14 April 2016 - Published in Atmos. Chem. Phys. Discuss.: 25 April 2016

Revised: 6 September 2016 - Accepted: 16 September 2016 - Published: 18 October 2016

\begin{abstract}
Carbon tetrachloride $\left(\mathrm{CCl}_{4}\right)$ is a long-lived radiatively active compound with the ability to destroy stratospheric ozone. Due to its inclusion in the Montreal Protocol on Substances that Deplete the Ozone Layer (MP), the last two decades have seen a sharp decrease in its largescale emissive use with a consequent decline in its atmospheric mole fractions. However, the MP restrictions do not apply to the use of carbon tetrachloride as feedstock for the production of other chemicals, implying the risk of fugitive emissions from the industry sector. The occurrence of such unintended emissions is suggested by a significant discrepancy between global emissions as derived from reported production and feedstock usage (bottom-up emissions), and those based on atmospheric observations (top-down emissions). In order to better constrain the atmospheric budget of carbon tetrachloride, several studies based on a combination of atmospheric observations and inverse modelling have been conducted in recent years in various regions of the world. This study is focused on the European scale and based on long-term high-frequency observations at three European sites, combined with a Bayesian inversion methodology. We estimated that average European emissions for 2006-2014 were $2.2( \pm 0.8) \mathrm{Gg} \mathrm{yr}^{-1}$, with an average decreasing trend of $6.9 \%$ per year. Our analysis identified France as the main source of emissions over the whole study period, with an average contribution to total European emissions of approximately $26 \%$. The inversion was also able to allow the lo-
\end{abstract}

calisation of emission "hot spots" in the domain, with major source areas in southern France, central England (UK) and Benelux (Belgium, the Netherlands, Luxembourg), where most industrial-scale production of basic organic chemicals is located. According to our results, European emissions correspond, on average, to $4.0 \%$ of global emissions for 20062012. Together with other regional studies, our results allow a better constraint of the global budget of carbon tetrachloride and a better quantification of the gap between top-down and bottom-up estimates.

\section{Introduction}

Carbon tetrachloride $\left(\mathrm{CCl}_{4}\right)$ is almost exclusively an anthropogenic compound, with its first use as a solvent, fire extinguisher, fumigant and rodenticide dating back to 1908 (Galbally, 1976; Happell et al., 2014). The rapid increase in its production, occurring between the 1950s and the 1980s, is linked mainly to its use as a solvent and also to the growth in the production of chlorofluorocarbons (CFCs) made from $\mathrm{CCl}_{4}$ (Simmonds et al., 1998). This led to a significant increase in the atmospheric mixing ratios of $\mathrm{CCl}_{4}$, as shown by firn air analysis (Butler et al., 1999; Sturrock et al., 2002). The tropospheric lifetime of $\mathrm{CCl}_{4}$ of 26-35 years (SPARC, 2013; Liang et al., 2014) is the result of the sum of three partial loss rates: loss in the stratosphere (Laube et al., 2013), 
degradation in the ocean (Yvon-Lewis and Butler, 2002) and degradation in the soil (Happell et al., 2014).

The main concerns about this long-lived chemical are linked to its ability in destroying the stratospheric ozone layer and, as a radiatively active gas, $\mathrm{CCl}_{4}$ has an ozone depleting potential (ODP) of 0.72 (Harris et al., 2014) and a global warming potential (GWP) of 1730 (Myhre et al., 2013). The inclusion of $\mathrm{CCl}_{4}$ in the Montreal Protocol on Substances that Deplete the Ozone Layer (MP) led to a sharp decrease in the large-scale emissive use of $\mathrm{CCl}_{4}$ and the consequent decline in its atmospheric mixing ratios was observed from the early 1990s (Fraser et al., 1994; Simmonds et al., 1998), with peak mole fractions of around 103 and 101 parts per trillion (ppt) in 1991 in the Northern Hemisphere $(\mathrm{NH})$ and Southern Hemisphere $(\mathrm{SH})$, respectively (Walker et al., 2000). In 2012, $\mathrm{CCl}_{4}$-measured global average mole fractions were 84.2 and $85.1 \mathrm{ppt}$ as measured by the AGAGE (Advanced Global Atmospheric Gases Experiment) and NOAA GMD (National Oceanic and Atmospheric Administration, Global Monitoring Division) ground-based sampling networks, respectively. The respective decrease rates from 2011 to 2012 were 1.2 and $1.6 \% \mathrm{yr}^{-1}$ (Carpenter et al., 2014). The contribution of $\mathrm{CCl}_{4}$ to total organic chlorine in the troposphere in 2012 was $10.3 \%$ (Carpenter et al., 2014).

Currently, emissive uses of $\mathrm{CCl}_{4}$ are banned under the MP in signatory countries. Production and use are allowed for feedstock in chemical manufacturing, for example, for perchloroethylene, hydrofluorocarbon (HFC) and pyrethroid pesticides production (UNEP, 2013). Chemical feedstocks should be converted into new chemicals, effectively destroying the feedstock, but fugitive emissions are possible. With no significant natural sources (Butler et al., 1999; Sturrock et al., 2002), the possible sources for $\mathrm{CCl}_{4}$ in the atmosphere are fugitive emissions from the industry sector (Simmonds et al., 1998; Fraser et al., 2014), generation during bleaching (Odabasi et al., 2014) or emissions from a legacy of $\mathrm{CCl}_{4}$ in old landfill (Fraser et al., 2014).

The persistence of such emissions is suggested by a discrepancy between global emissions as derived from reported production and feedstock usage (bottom-up emissions), and those based on atmospheric observations (top-down emissions). Assuming a total atmospheric lifetime of 26 years and the observed trend in the atmosphere, the top-down global $\mathrm{CCl}_{4}$ emission estimates suggest that the 2011-2012 global $\mathrm{CCl}_{4}$ emissions are 57 (40-74) $\mathrm{Gg} \mathrm{yr}^{-1}$, a value that is at least 1 order of magnitude higher than estimates based on industrial use (Carpenter et al., 2014). In addition the persistence of an inter-hemispheric gradient of about $1.3 \mathrm{ppt}(\mathrm{NH}$ minus SH) since 2006 shows that $\mathrm{CCl}_{4}$ is still emitted in the NH (Carpenter et al., 2014). Similar results have been obtained by Liang et al. (2014), who deduced that the mean global emissions during 2000-2012 were $39 \mathrm{Gg} \mathrm{yr}^{-1}$ (34$45 \mathrm{Gg} \mathrm{yr}^{-1}$ ) with a calculated total atmospheric lifetime for $\mathrm{CCl}_{4}$ of 35 (32-37) years.
In order to better constrain the $\mathrm{CCl}_{4}$ budget, several topdown studies have been conducted in recent years focused on the global and regional scale, the top-down approach having been recognised as an important independent verification tool for bottom-up reporting (Nisbet and Weiss, 2010; Weiss and Prinn, 2011; Lunt et al., 2015).

Xiao et al. (2010) used a three-dimensional inversion model and global $\mathrm{CCl}_{4}$ observations (AGAGE and NOAAGMD) to derive emissions from eight world regions over the 1996-2004 period, identifying Southeast Asia as being responsible for more than half of the global industrial emissions, which they estimated as $74.1 \pm 4.3 \mathrm{Gg} \mathrm{yr}^{-1}$ (9-year average).

The role of China as a significant source region of $\mathrm{CCl}_{4}$ has been highlighted by Vollmer et al. (2009), who, based on 18-month continuous high-frequency observations (October 2006-March 2008) conducted at a site in the North China Plain and a Bayesian inversion modelling approach, calculated Chinese emissions to be $15 \mathrm{Gg} \mathrm{yr}^{-1}\left(10-22 \mathrm{Gg} \mathrm{yr}^{-1}\right)$ out of their global estimates of $53 \pm 30 \mathrm{Gg} \mathrm{yr}^{-1}$.

According to Fraser et al. (2014), top-down Australian emissions during 1996-2011 have declined from 0.25-0.35 to $0.12-0.18 \mathrm{Gg} \mathrm{yr}^{-1}$, a decline of $5 \% \mathrm{yr}^{-1}$. In this study, potential sources other than those arising from production, transport and use were identified and on the basis of an analysis of pollution episodes were likely to be associated with contaminated soils, toxic waste treatment facilities and chloralkali plants.

In 2012, Miller et al. (2012) used a ${ }^{14} \mathrm{C}$-based top-down method to derive an average emission of $0.4 \mathrm{Gg} \mathrm{yr}^{-1}$ from the USA during 2004-2009, corresponding to $4 \%$ of the global emissions given in Montzka et al. (2011). Emission estimates by Hu et al. (2016) during 2008-2012 were 4.0 (2.0$6.5) \mathrm{Gg} \mathrm{yr}^{-1}$. This number is 2 orders of magnitude greater than emissions reported to the US Environmental Protection Agency Toxics Release Inventory over the same period and 1 order of magnitude greater than the previous estimates given by Miller et al. (2012). Estimates by Hu et al. (2016) were derived using observations from a large observation network including multiple sites across the USA and both a Bayesian and geostatistical inverse analyses.

For Europe, the most recent estimates are given in the above cited paper by Xiao et al. (2010), who reported that Europe has been responsible, during 1996-2004, for $4 \%$ of global emissions. However, this study, based on observations conducted at global baseline sites, did not derive regional variations that likely occur across the different European countries and that could help in identifying specific emission sources, including those unrelated to reported production.

In order to derive $\mathrm{CCl}_{4}$ European emissions at the country scale we conducted a study based on long-term, highfrequency $\mathrm{CCl}_{4}$ observations carried out at three European sites combined with FLEXPART (FLEXible PARTicle dispersion model) and the Bayesian inversion approach de- 
veloped by Seibert $(2000,2001)$, improved by Eckhardt et al. (2008) and Stohl et al. $(2009,2010)$ and recently applied to derive emissions of halogenated species at the European scale (Maione et al., 2014; Graziosi et al., 2015).

Even though major source regions are likely to be located in East Asia, our results, in combination with those obtained from other regional studies, are useful for better assessment of the global budget of $\mathrm{CCl}_{4}$ and better evaluation of the extent to which future emissions will affect the evolution of the equivalent effective stratospheric chlorine.

\section{Method}

\subsection{Measurements}

In Europe, long-term high-frequency observations of $\mathrm{CCl}_{4}$ are available from three sites, all labelled as WMO GAW (World Meteorological Organization, Global Atmosphere Watch) stations, and AGAGE and affiliated stations: Mt. Cimone, CMN (Italy); Jungfraujoch, JFJ (Switzerland); and Mace Head, MHD (Ireland). CMN and JFJ are mountain stations occasionally affected by air masses from the polluted boundary layer; the MHD baseline station is mostly affected by oceanic air masses and occasionally by air masses from Ireland, the UK and continental Europe. $\mathrm{All} \mathrm{CCl}_{4}$ data used in this paper are available from the AGAGE network. Different instrumentations and protocols are used to measure in situ $\mathrm{CCl}_{4}$ at each station: $\mathrm{CMN}$ uses a gas chromatograph with mass spectrometric detection (GC-MS) with sample enrichment on adsorbent trap by a commercial thermal desorber (Maione et al., 2013), JFJ uses a gas chromatograph with mass spectrometer detection with sample enrichment on a custom-built thermal desorber Medusa GC-MS (Miller et al., 2008), and MHD uses a gas chromatograph with electron-capture detection (GC-ECD) without sample enrichment (Prinn et al., 2000).

All the measurements are reported using the Scripps Institution of Oceanography (SIO) SIO-05 gravimetric primary calibration scale: ambient air measurements are routinely calibrated against whole air working standards that have been filled locally, using a bracketing technique, to override shortterm instrumental drifts. Working standards are then referenced on a weekly basis to a tertiary tank (provided and calibrated by SIO) on site for the GC-MS measurements, i.e. CMN and JFJ. For the MHD GC-ECD instrument the tertiary tanks used as the working standard are prepared and calibrated at SIO at least twice, at both the beginning and end of the life of the tank (Prinn et al., 2000; Miller et al., 2008). For this reason the contribution of the scale transfer (calibration) uncertainty to the total measurement uncertainty is minimised among stations, constraining the error estimate to the instrumental precision, calculated as the standard deviation $(1 \sigma)$ of the repeated working standard measurements for the covered period, that is typical for each site/setup and almost constant over the years of observation: $\mathrm{CMN} \pm 0.39 \mathrm{ppt}$, $\mathrm{JFJ} \pm 0.86 \mathrm{ppt}$ and $\mathrm{MHD} \pm 0.24 \mathrm{ppt}$. In addition, the analytical systems at the three stations are operated via the Linuxbased chromatography software GCWerks (http://gcwerks. com) developed within the AGAGE programme.

\subsection{Inverse modelling}

Observations have been combined with 20-day backward trajectories of the Lagrangian particle dispersion model FLEXPART (Stohl et al., 2005). FLEXPART runs are based on the European Centre for Medium-range Weather Forecast (ECMWF) wind fields using 3-hourly ECMWF reanalyses (ERA-Interim) (analysis fields are at 00:00, 06:00, 12:00 and 18:00 UTC, and $3 \mathrm{~h}$ forecasts are at 03:00, 09:00, 15:00 and 21:00 UTC) with $1^{\circ} \times 1^{\circ}$ horizontal resolution and 91 vertical levels. The emission sensitivity map of source-receptor relationships (SRRs) generated using the three European stations is reported in Fig. 1. The obtained SRRs combined with an a priori emission field allowed us to estimate the a posteriori emission flux for the European geographical domain (EGD) using the Bayesian inversion technique.

With the aim of obtaining the best performance of the model in terms of the correlation coefficient between the observations and the modelled time series, we tested seven a priori emission fields based on different combinations of (i) $\mathrm{CCl}_{4}$ emission fluxes estimated by Xiao et al. (2010), (ii) $\mathrm{CCl}_{4}$ emissions in the European Pollutant Release and Transfer Register (E-PRTR, http://prtr.ec.europa.eu/\#/ home), reporting $\mathrm{CCl}_{4}$ atmospheric emissions higher than $100 \mathrm{~kg} \mathrm{yr}^{-1}$ from 30000 industrial facilities in the domain from 2007 to 2013, (iii) information on the potential chlorine production from chlor-alkali plants as in the Euro Chlor report (http://www.eurochlor.org), providing information on the chlorine potential production of each plant from 2006 to 2014 , (iv) $\mathrm{CCl}_{4}$ emission factors from the chlor-alkali industry derived by Brinkmann et al. (2014) and Fraser et al. (2014), and (v) diffusive emissions from the use of bleachcontaining cleaning agents (Odabasi et al., 2014). In the seven a priori emission fields tested, the parameterisation range was (i) from 0.6 to $4.4 \mathrm{Gg} \mathrm{yr}^{-1}$ for the total a priori emission flux from the EGD, (ii) from 3 to $80 \%$ for the contribution of industrial activities to the total EGD flux and (iii) from 0.03 to $0.4 \mathrm{~kg} \mathrm{CCl}_{4}$ for each tonne of chlorine produced by the chlor-alkali plants listed in Euro Chlor.

Despite these large ranges of values, the resulting EGD emission fluxes converged to very similar values, well within the inversion uncertainty, confirming the robustness of the method. For this study we used an "ensemble" a priori emission field that showed the best model performance. The detailed description of the tests performed is reported in the Supplement.

The inversion grid consists of more than 5000 grid boxes with different horizontal resolutions ranging from $0.5^{\circ}$ by $0.5^{\circ}$ to $2.0^{\circ}$ by $2.0^{\circ}$ latitude-longitude in order to assure sim- 


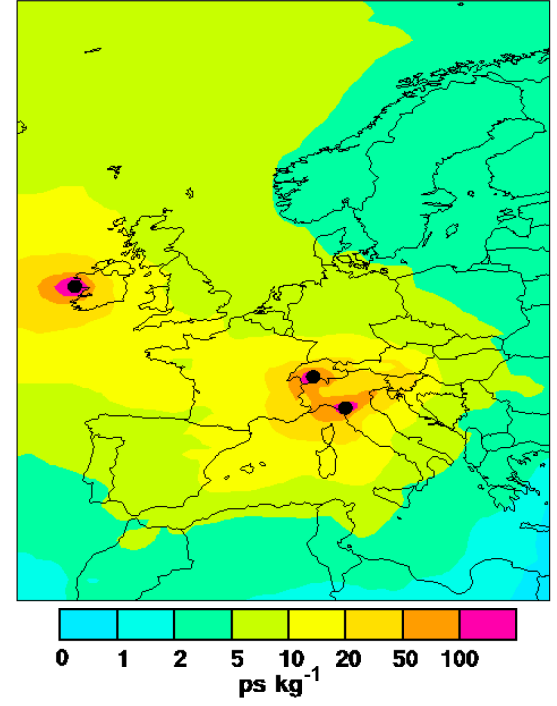

Figure 1. Footprint emission sensitivity in picoseconds per kilogram $\left(\mathrm{ps} \mathrm{kg}^{-1}\right)$ obtained from FLEXPART. 20-day backward calculations averaged over all model calculations over 2 years (January 2008-December 2009). Measurement sites are marked with black dots.

ilar weight on the inversion result. We estimated 9 years of European emissions, from January 2006 to December 2014. During this period, the inversion was run using the only two stations (CMN and MHD) in which observations were available. During 2010-2014, data from JFJ were also used. A detailed description of the inversion technique and of the related uncertainty is given in the Supplement.

\section{Results and discussion}

\subsection{Time series statistical analysis}

$\mathrm{CCl}_{4}$ time series (individual data) at three European stations are reported in Fig. 2. Using a statistical approach described in Giostra et al. (2011) we discriminate background mole fractions from elevations above the baseline due to pollution episodes. The CMN time series shows a dip in 2006 that cannot be explained by instrumental reasons. However, it should be noted that the inversion results are affected by the extent of the enhancements above the baseline rather than by the baseline absolute values. Therefore the 2006 CMN data have not been flagged.

The background data line at JFJ is thicker, reflecting the greater noise in the signal due to inherent problems in measuring $\mathrm{CCl}_{4}$ with the Medusa GC-MS. Therefore, we performed some tests running the inversion after removing JFJ time series. Despite the quite noisy JFJ time series, we found a difference in the estimated emissions for the whole European domain to be $<5 \%$. This can be due to the overlapping of the footprint of CMN and JFJ receptors.
The monthly mean background mole fractions have been used to derive $\mathrm{CCl}_{4}$ atmospheric trends, applying the empirical model described in Simmonds et al. (2004). Atmospheric trends in the background mole fractions over the common period (July 2010-December 2014) are $-1.5 \pm 0.2$, $-1.2 \pm 0.1$ and $-1.3 \pm 0.1 \% \mathrm{yr}^{-1}\left(R^{2}=0.93,0.99,0.98\right)$, at CMN, MHD and JFJ respectively. Such values are consistent with global trends given in Carpenter et al. (2014).

\subsection{Inversion results}

$\mathrm{CCl}_{4}$ emission intensity from the EGD and the emission distribution within the same domain has been estimated using the European observations and the described Bayesian inversion technique. As shown in Fig. 3, the main deviations between our estimates (flux $\mathrm{x}_{\text {post }}$ ) and the a priori values (flux $x_{\text {prior }}$ ) are found in 2006 and 2013-2014. The relative percentage bias, given by $\left(\right.$ flux $_{\text {post }}-$ flux $\left._{\text {prior }}\right) /$ flux $_{\text {prior }} \times 100$, ranges from +15 to $-37 \%$, as shown in the bottom panel of Fig. 3. The emission flux uncertainty decreases from $180 \%$ of the a priori to $33 \%$ of the a posteriori emission field (average over the study period), supporting the reliability of the results. More details on the method performance are given in the Supplement.

\subsubsection{European emissions and emission trends}

The inversion results indicate average EGD emissions during the study period of $2.2( \pm 0.8) \mathrm{Gg} \mathrm{yr}^{-1} \cdot \mathrm{CCl}_{4}$ total emissions from the EGD have decreased from $2.8( \pm 1.0) \mathrm{Gg} \mathrm{yr}^{-1}$ in 2006 to $1.5( \pm 0.5) \mathrm{Gg} \mathrm{yr}^{-1}$ in 2014 , corresponding to an average EGD decreasing trend of $6.9 \%$ per year (Fig. 4). To put European emissions into a global perspective, we compared our results with global estimates. Global top-down emissions as derived from atmospheric measurements are available only until 2012 (Carpenter et al., 2014). For consistency, this comparison was made considering the same time period when we estimated EGD average emissions of $2.5 \mathrm{Gg} \mathrm{yr}^{-1}$, corresponding to $4 \%$ of the global average. The plot in Fig. 4 also shows a comparison between the EGD and the global emission trends. During 2006-2012, the EGD estimates show an average trend $-2.9 \% \mathrm{yr}^{-1}$ compared with a global trend, for the same period, of $-2.2 \% \mathrm{yr}^{-1}$. For comparison, during 2004-2011 the decreasing trend in Australian emissions was $5 \% \mathrm{yr}^{-1}$ (Fraser et al., 2014).

EGD and macro area emission estimates for the individual years are given in Table 1. Such figures cannot be reconciled with potential emissions estimated from European production data reported to UNEP (United Nations Environment Programme) that, along the study period, with the exception of 2012, are negative, being calculated as the amount of controlled substances produced minus the amount destroyed and the amount entirely used as feedstock. The discrepancy between the inversion results and the emissions reported to UNEP by industry persists also if $2 \%$ of fugi- 

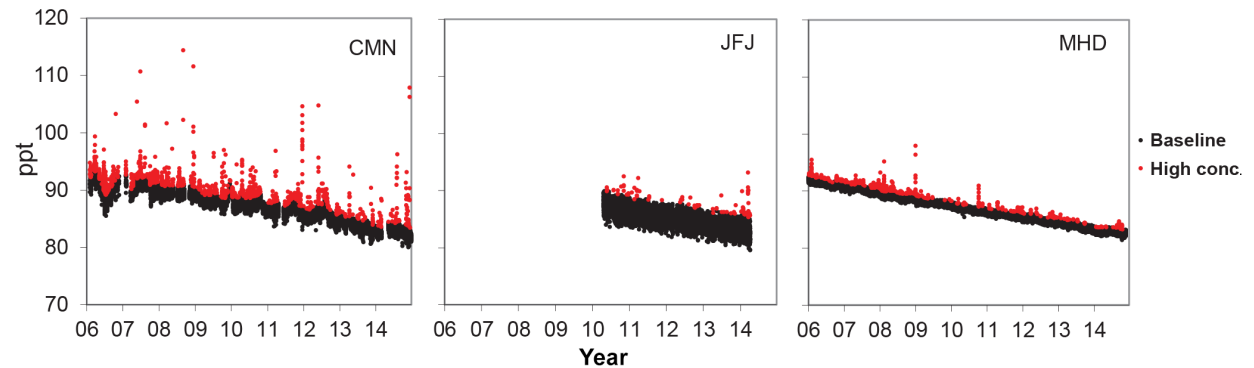

Figure 2. $\mathrm{CCl}_{4}$ time series at three European sites: Mt. Cimone, CMN (Italy); Jungfraujoch, JFJ (Switzerland); and Mace Head, MHD (Ireland). Black dots: baseline in parts per trillion (ppt). Red dots: enhancements above the baseline.

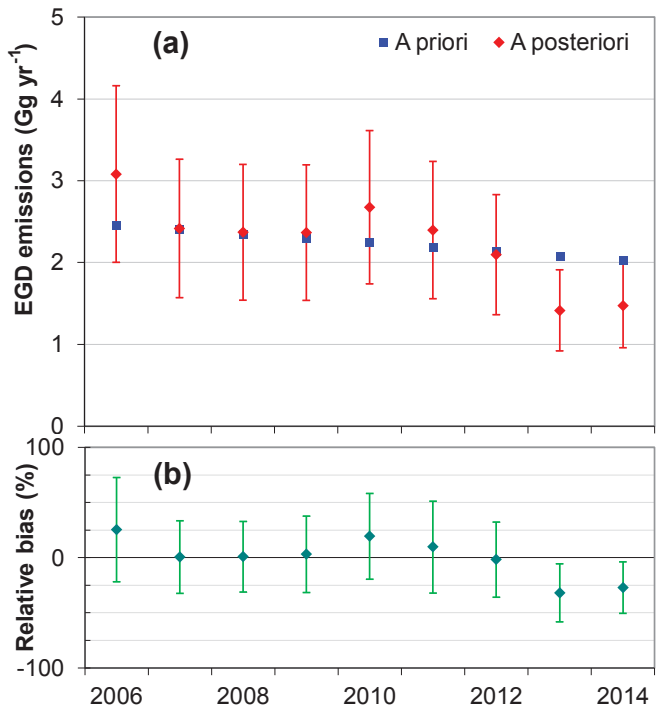

Figure 3. (a) Comparison between the a priori (blue squares) and a posteriori (red diamonds) $\mathrm{CCl}_{4}$ emission fluxes from the European geographical domain during 2006-2014. (b) Percentage relative bias between the a priori and a posteriori time series (green diamonds).

tive emissions and $75 \%$ of destruction efficiency are hypothesised (UNEP production database, http://ozone.unep.org/). Also when comparing our estimates with emissions from industrial activities declared to the E-PRTR, we found the EPRTR to be strongly (on average 35 times) underestimated, reinforcing the incompleteness of available information.

\subsubsection{Emission distribution within the domain and emission hot spots}

The obtained EGD a posteriori emission fluxes differ from the a priori both in intensity (as described above) and in spatial distribution.

In order to quantitatively assess the contribution to the total European emissions of $\mathrm{CCl}_{4}$ from the various countries, we divided our domain into 10 macro areas (abbreviations given in Table 1), whose extension is related to the SRRs of

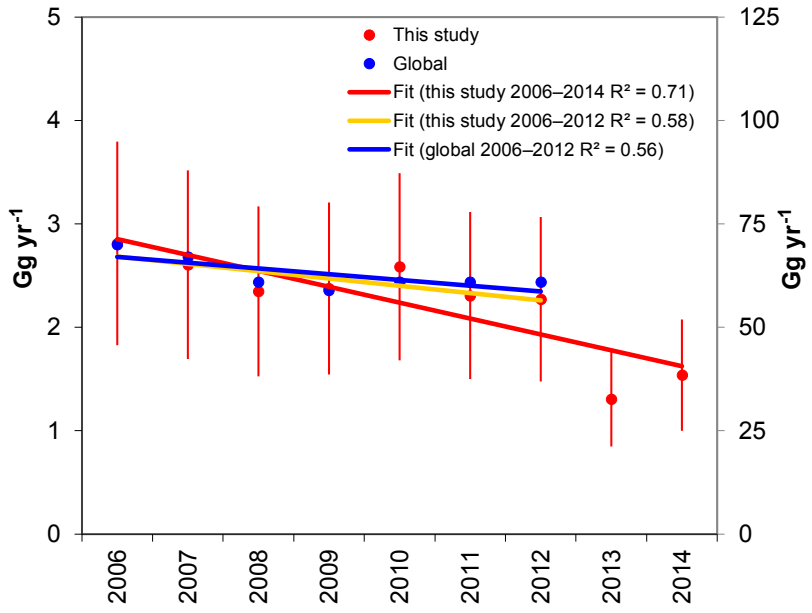

Figure 4. European geographical domain $\mathrm{CCl}_{4}$ emission fluxes derived in this study (red dots, left axis) compared with the global ones reported in Carpenter et al. (2014) (blue dots, right axis). Red line: linear regression of our estimates during 2006-2014 $\left(-6.9 \% \mathrm{yr}^{-1}\right)$. Orange line: linear regression of our estimates during 2006-2012 $\left(-2.9 \% \mathrm{yr}^{-1}\right)$. Blue line: linear regression of global fluxes during 2006-2012 (-2.2\% $\left.\mathrm{yr}^{-1}\right)$.

the area (see Fig. 1). Emissions from the single macro areas and the associated uncertainty (see Supplement) are reported in Table 1 and in Fig. 5a. Figure 5b shows the percentage contribution from the single macro areas.

Our estimates identify FR as the main emitter in the EGD over the entire study period, with an average contribution of approximately $26 \%$. Six macro areas (ES-PT $>$ NEE $>$ DEAT $>$ SEE $>$ UK-IE $>$ IT) contribute between 13.2 and $7.6 \%$, while the remaining regional contributions average $4 \%$ each. Emissions from FR reached a maximum in 2010. Emissions from IT and $\mathrm{CH}$ show a faster decreasing trend with respect to the average EGD rate and the remaining macro areas decreased according to the overall average EGD emissions. As a result, starting from 2008, the percent contribution of FR is about $30 \%$ of total EGD emissions.

Beside the overall picture given by the analysis of the aggregated macro area emission estimates, the analysis of the 
Table 1. Carbon tetrachloride emission estimates $\left(\mathrm{Gg} \mathrm{yr}^{-1}\right)$ and associated uncertainty, percent yearly emission trends and 9-year average percent contributions from the European geographical domain (EGD) and from the 10 macro areas within the EGD over the study period. Macro areas listed according to their emission intensity are as follows: FR (France), ES-PT (Spain, Portugal), NEE (Poland, Czech Republic, Slovakia, Lithuania, Latvia, Estonia, Hungary, Romania, Bulgaria), DE-AT (Germany, Austria), SEE (Slovenia, Croatia, Serbia, BosniaHerzegovina, Montenegro, Albania, Greece), UK-IE (United Kingdom, Republic of Ireland), IT (Italy), SCA (Norway, Sweden, Finland, Denmark), Benelux (Belgium, the Netherlands, Luxembourg) and CH (Switzerland).

\begin{tabular}{|c|c|c|c|c|c|c|c|c|c|c|c|}
\hline \multirow[t]{2}{*}{ Areas } & \multicolumn{9}{|c|}{$\mathrm{CCl}_{4}$ yearly emissions $\left(\mathrm{Mg} \mathrm{yr}^{-1}\right)$} & \multirow{2}{*}{$\begin{array}{r}\text { Trend } \\
\% \mathrm{yr}^{-1}\end{array}$} & \multirow[t]{2}{*}{ Mean } \\
\hline & 2006 & 2007 & 2008 & 2009 & 2010 & 2011 & 2012 & 2013 & 2014 & & \\
\hline EGD & $2812 \pm 1058$ & $2606 \pm 853$ & $2348 \pm 807$ & $2376 \pm 800$ & $2586 \pm 837$ & $2308 \pm 913$ & $2272 \pm 822$ & $1305 \pm 488$ & $1538 \pm 485$ & -6.9 & \\
\hline FR & $405 \pm 109$ & $519 \pm 140$ & $671 \pm 181$ & $563 \pm 152$ & $849 \pm 229$ & $597 \pm 161$ & $572 \pm 154$ & $391 \pm 106$ & $542 \pm 146$ & 0.0 & 26.2 \\
\hline ES-PT & $519 \pm 189$ & $444 \pm 162$ & $151 \pm 55$ & $323 \pm 118$ & $303 \pm 110$ & $405 \pm 148$ & $248 \pm 90$ & $87 \pm 32$ & $257 \pm 94$ & -10.1 & 13.2 \\
\hline NEE & $311 \pm 118$ & $468 \pm 177$ & $318 \pm 120$ & $209 \pm 79$ & $399 \pm 151$ & $123 \pm 47$ & $305 \pm 115$ & $81 \pm 31$ & $226 \pm 86$ & -9.9 & 11.8 \\
\hline DE-AT & $290 \pm 81$ & $396 \pm 110$ & $176 \pm 49$ & $327 \pm 91$ & $319 \pm 89$ & $181 \pm 50$ & $206 \pm 57$ & $166 \pm 46$ & $161 \pm 45$ & -8.7 & 11.0 \\
\hline SEE & $205 \pm 120$ & $76 \pm 45$ & $286 \pm 168$ & $291 \pm 171$ & $213 \pm 125$ & $342 \pm 201$ & $471 \pm 277$ & $100 \pm 59$ & $38 \pm 22$ & -1.3 & 9.8 \\
\hline UK-IE & $241 \pm 60$ & $212 \pm 53$ & $269 \pm 67$ & $181 \pm 45$ & $149 \pm 37$ & $175 \pm 44$ & $88 \pm 22$ & $138 \pm 35$ & $132 \pm 33$ & -9.7 & 8.0 \\
\hline IT & $405 \pm 117$ & $208 \pm 60$ & $179 \pm 52$ & $265 \pm 77$ & $228 \pm 66$ & $131 \pm 38$ & $98 \pm 28$ & $70 \pm 20$ & $43 \pm 12$ & -19.9 & 7.6 \\
\hline Benelux & $88 \pm 15$ & $189 \pm 32$ & $121 \pm 20$ & $167 \pm 28$ & $109 \pm 18$ & $95 \pm 16$ & $224 \pm 38$ & $82 \pm 14$ & $98 \pm 16$ & -1.9 & 5.9 \\
\hline SCA & $287 \pm 236$ & $88 \pm 72$ & $95 \pm 78$ & $46 \pm 38$ & $11 \pm 9$ & $252 \pm 207$ & $44 \pm 36$ & $175 \pm 144$ & $35 \pm 29$ & -9.3 & 5.4 \\
\hline $\mathrm{CH}$ & $61 \pm 12$ & $6 \pm 1$ & $82 \pm 16$ & $4 \pm 1$ & $6 \pm 1$ & $7 \pm 1$ & $16 \pm 3$ & $15 \pm 3$ & $6 \pm 1$ & -23.8 & 1.0 \\
\hline
\end{tabular}
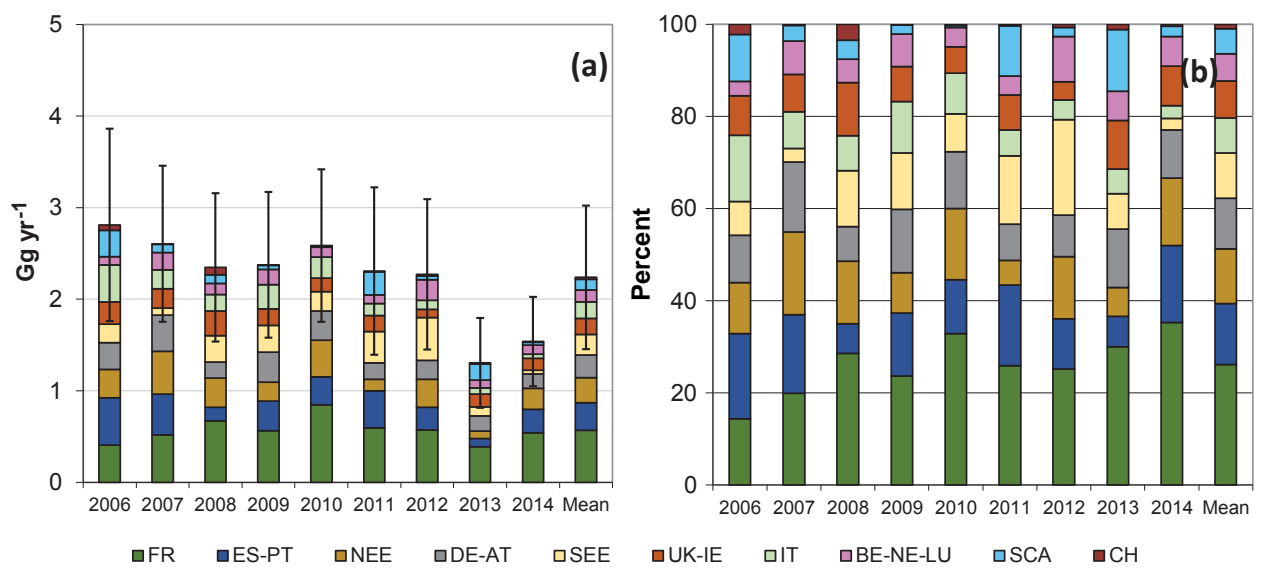

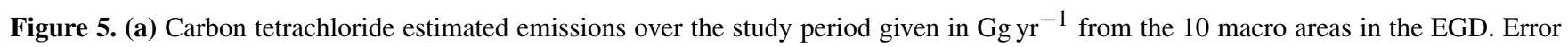
bars represent the uncertainty in emissions as derived from the inversion routine (see Supplement). (b) Yearly percent contributions of the individual macro areas to total EGD emissions.

spatial distribution of the emission fluxes provides additional insights. The map in Fig. 6 shows the a posteriori average distribution of emission fluxes over the study period, obtained with the "ensemble" a priori emission field.

The geo-referenced emission sources as reported by the E-PRTR inventory are represented as open circles, with the size of the circles referring to the amount released. Crosses refer to the geo-referenced Euro Chlor chlor-alkali plants, for which the information on $\mathrm{CCl}_{4}$ fluxes is not available.

Figure 6 shows how, in general, the localisation of the main emission sources declared by E-PRTR is well captured by the inversion, as in the case of southern France, central England (UK) and Benelux. In addition, many hot spots are coincident with the chlor-alkali industries reported in Euro Chlor; see e.g. the Bavarian region in southern Germany, Sardinia (Italy) and southern Spain. These hot spots are observed even when the inversion is run using the a priori emission field that does not include the E-PRTR and/or Euro Chlor information on industrial emissions (not shown), indicating that the emission hot spots are not forced by the a priori flux.

In order to facilitate the comprehension of the map in Fig. 6, we compared the E-PRTR emission fluxes with estimates from the grid cells included in the corresponding hot spot areas identified through the inversion. We found that emission fluxes for the hot spots in southern France and central England were 1 order of magnitude larger than the reported ones and for Benelux emissions were 5 times larger than those declared in the E-PRTR inventory. The results suggest one or more of the following: an under-reporting of current emissions, the occurrence of additional sources not reported by the E-PRTR inventory, emissions from the chlor-alkali industry and/or from historical production (such as landfill) (Fraser et al., 2014). 


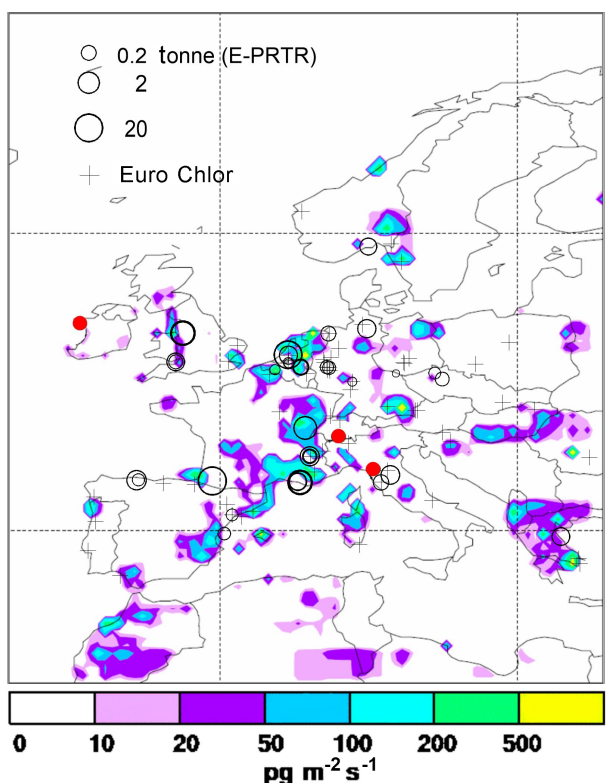

Figure 6. Average a posteriori distribution of $\mathrm{CCl}_{4}$ emissions from the European geographical domain over the study period. Measurement stations are marked with red dots. Open circles represent emissions into the atmosphere as reported by the E-PRTR inventory. Crosses correspond to the location of chlor-alkali plants listed in Euro Chlor.

\subsubsection{Comparison with NAME}

For comparison, we ran an alternative top-down approach based on observations at MHD combined with the UK Met Office Numerical Atmospheric-dispersion Modelling Environment (NAME) to simulate the dispersion and an iterative best fit technique (the simulated annealing) to derive regional emission estimates (Manning et al., 2011). This alternative top-down approach differs from our procedure in both the dispersion model and in the inversion technique, as well as in the absence of an a priori emission field and in the use of a single receptor. The use of a single station narrows the study area to a sub-EGD that includes eight countries in northwest Europe (NWEU), i.e. Benelux, Denmark (DK), DE, FR and UK-IE. Figure 7 reports a comparison of the results obtained using the two different approaches for the UK only and for the NWEU domain. Overall, a fair agreement is observed, with the differences between the two estimates always within the emission uncertainty. Such encouraging results support the reliability of the estimated emissions.

\subsection{Industrial emission factors}

UNEP (2009) identified chlor-alkali plants as potential accidental sources of $\mathrm{CCl}_{4}$. Consistently in the USA, $\mathrm{Hu}$ et al. (2016) reported emission hot spots in areas where chloralkali plants are located. In addition, Fraser et al. (2014) suggest that plants based on the outdated $\mathrm{Hg}$ cells technology

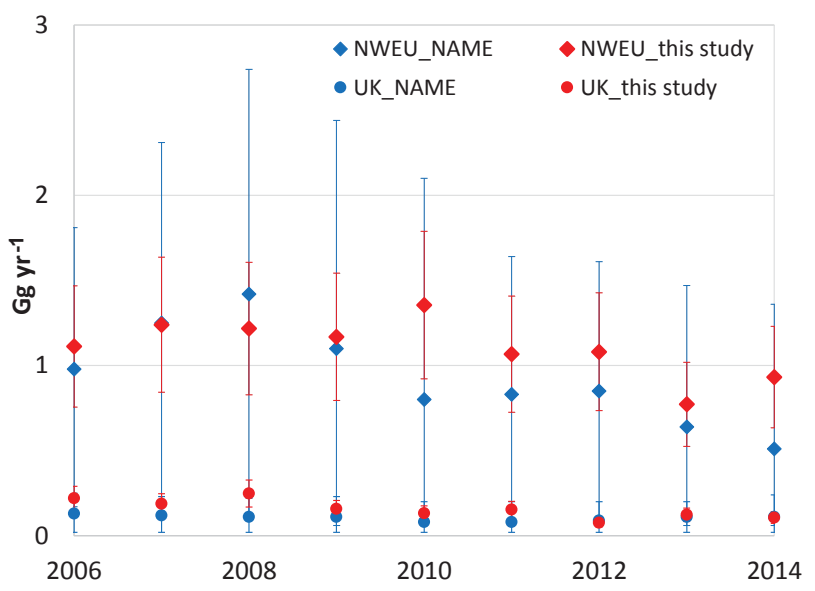

Figure 7. Comparison between emissions from the UK (circles) and the NWEU domain (diamonds) estimated through the NAME (blue) and the Bayesian (red) approach.

could be the main responsible source of $\mathrm{CCl}_{4}$ emissions. In Europe, the last two decades have seen efficiency improvements in the chlor-alkali production technologies and Brinkmann et al. (2014) estimated an emission factor (EF) of $0.03 \mathrm{~kg} \mathrm{CCl}_{4} \mathrm{t}^{-1} \mathrm{Cl}$ produced. From our estimates we derived an average $\mathrm{EF}$ from the EGD of $0.21 \mathrm{~kg} \mathrm{CCl}_{4} \mathrm{t}^{-1} \mathrm{Cl}$ produced during 2010-2014 that, as shown in Sect. 3.2.2, follows the distribution of industrial plants. These figures can be compared against a value of 0.39 calculated (P. J. Fraser, personal communication, 2016) for 2008-2011 on the basis of US emission estimates given by $\mathrm{Hu}$ et al. (2016), and a value of 0.41 for 2004-2011 based on Australian emissions (Fraser et al., 2014). Indications of the reasons of discrepancies between our EF and that given by Brinkmann et al. (2014), and between our EF and that calculated for the USA and Australia, could be provided by an analysis at the macro area level. Our estimates show how the emission factors are not homogeneous across the macro areas in the EGD, with DE-AT, Benelux and SCA exhibiting EFs of the same order of magnitude of those given in Brinkmann et al. (2014), whereas values for the remaining macro areas are 1 order of magnitude higher. Indeed, $\mathrm{CCl}_{4}$ emission fluxes estimated for the different macro areas of the EGD (reported in Fig. 5), even after subtraction of the diffuse share (following the population density), are not directly related to the chlorine potential production in the same macro areas (Euro Chlor, 2014; for further details see Fig. S6, in the Supplement). A reason of this lack of correlation could be ascribed to the inhomogeneous penetration of the different technologies in the various EGD macro areas (Euro Chlor, 2014; for further details see Fig. S7, in the Supplement), suggesting that $\mathrm{CCl}_{4}$ fluxes are more related to the adopted technology rather than to the amount of chlorine produced. The determination of such emission rates is made even more difficult by additional factors, such as the lack of obligation, of the chlor-alkali plants 
allowed to use $\mathrm{CCl}_{4}$ as process agent for the elimination of nitrogen trichloride and the recovery of chlorine from tail gases, to report the actual amount used and/or the transfer of the allocated quota (Brinkmann et al., 2014).

\section{Conclusions}

In this study we have estimated European emissions of carbon tetrachloride combining atmospheric observations at three European sites with a Lagrangian dispersion model (FLEXPART) and a Bayesian inversion method. This procedure allowed us to assess the $\mathrm{CCl}_{4}$ emission field with a high spatial resolution within the domain.

We estimated average emissions from the European geographical domain during 2006-2014 of $2.2( \pm 0.8) \mathrm{Gg} \mathrm{yr}^{-1}$, with a decreasing rate of $6.9 \%$ per year. Such an emission flux corresponds to $4 \%$ of the global emission estimates given by Carpenter et al. (2014) over the period 2006-2012.

When comparing emissions derived with the top-down approach with those evaluated through bottom-up methods, large discrepancies are observed. Such discrepancies are expected with regard to the information contained in the UNEP database, which reports production (without allowing for stock change but quoting destruction as a negative production) and consumption for emissive uses. Also, emissions reported in the E-PRTR inventory, which should include data related to those industrial processes (including waste treatment) that can potentially emit $\mathrm{CCl}_{4}$, represent only about $3 \%$ of our estimates. However, in spite of the discrepancy in the quantification of emissions, the inversion is able to localise the main source areas reported in the E-PRTR. In addition, we note that many areas where chlor-alkali plants are located are identified as source areas by the inversion, even when the information related to such plants is not included in the a priori emission field. Thus, the estimated a posteriori emission flux seems to confirm that chlor-alkali plants are mainly responsible for $\mathrm{CCl}_{4}$ emissions in the domain (UNEP, 2009).

We also calculated the rate of $\mathrm{CCl}_{4}$ emitted into the atmosphere per amount of chlorine produced in the chlor-alkali industry, obtaining an average emission factor for Europe of $0.21 \mathrm{~kg} \mathrm{CCl}_{4} \mathrm{t}^{-1}$ chlorine produced. This value is lower than those for the US (0.39) and Australian (0.41) plants. This European average emission factor includes a high variability across the various macro areas in the domain, showing the inadequacy of the chlorine potential production as a proxy of $\mathrm{CCl}_{4}$ emissions as well as the relevance of the chlorine production technologies adopted by the chlor-alkali industry (including the direct use of $\mathrm{CCl}_{4}$ to abate nitrogen trichloride emissions).

To summarise, this study allowed us to estimate $\mathrm{CCl}_{4}$ emission fluxes at the European regional scale. Thanks to the high sensitivity in most of the EGD, the emission field can be reconstructed with a resolution level able to show, for each country, the main inconsistencies between the national emission declarations and the estimates based on atmospheric observations. Our results could allow a better constraint of the global budget of $\mathrm{CCl}_{4}$ and a better quantification of the gap between top-down and bottom-up estimates, even if our estimates together with those derived from other regional studies (Fraser et al., 2014; Hu et al., 2016; Vollmer et al., 2009) still do not add up to the total amount required to comply with the current atmospheric abundance as in Carpenter et al. (2014). Such a discrepancy can be ascribed either to missing sources or to a lack of data from unsampled regions of the world or to an incorrect evaluation of $\mathrm{CCl}_{4}$ atmospheric lifetime, as recently shown in a study by Butler et al. (2016), whose reconsideration of $\mathrm{CCl}_{4}$ total lifetime could contribute to narrowing the gap between top-down and bottom-up estimates.

\section{Data availability}

The time series of $\mathrm{CCl}_{4}$ measured at the three sites are available at the World Data Centre for Greenhouse Gases, http://ds.data.jma.go.jp/gmd/wdcgg/wdcgg.html (Contributors AGAGE science team, 2016). The FLEXPART code can be downloaded from https://www.flexpart.eu/. FLEXINVERT open software can be downloaded from http:// flexinvert.nilu.no/.

\section{The Supplement related to this article is available online at doi:10.5194/acp-16-12849-2016-supplement.}

\begin{abstract}
Acknowledgements. We would like to thank Paul J. Fraser for his insightful review and comments on the paper, as these comments led to an improvement in our work. We acknowledge the AGAGE science team as well as the station personnel for their support in conducting in situ measurements. Measurements at Jungfraujoch are supported by the Swiss Federal Office for the Environment (FOEN) through the project HALCLIM and by the International Foundation High Altitude Research Stations Jungfraujoch and Gornergrat (HFSJG). Measurements at Mace Head are supported by the Department of Energy \& Climate Change (DECC, UK) (contract GA0201 with the University of Bristol). The InGOS EU FP7 Infrastructure project (grant agreement no. 284274) also supported the observation and calibration activities. The Interuniversity Consortium CINFAI (Consorzio Interuniversitario Nazionale per la Fisica delle Atmosfere e delle Idrosfere) supported F. Graziosi with a grant (RITMARE Flagship Project). The O. Vittori station is supported by the National Research Council of Italy.
\end{abstract}

Edited by: M. Chipperfield

Reviewed by: P. J. Fraser and two anonymous referees 


\section{References}

Brinkmann, T., Giner Santonja, G., Schorcht, F., Roudier, S., and Delgado Sancho, L.: Industrial Emissions Directive 2010/75/EU, Integrated Pollution Prevention and Control, Science and Policy Reports, Best Available Techniques (BAT), Reference Document for the Production of Chlor-alkali, EC-JRC, Joint Research Centre of the European Commission, Luxembourg: Publications Office of the European Union, 2014.

Butler, J. H., Battle, M., Bender, M. L., Montzka, S. A., Clarke, A. D., Saltzman, E. S., Sucher, C. M., Severinghaus, J. P., and Elkins, J. W.: A record of atmospheric halocarbons during the twentieth century from polar firn air, Nature, 399, 749-755, 1999.

Butler, J. H., Yvon-Lewis, S. A., Lobert, J. M., King, D. B., Montzka, S. A., Bullister, J. L., Koropalov, V., Elkins, J. W., Hall, B. D., Hu, L., and Liu, Y.: A comprehensive estimate for loss of atmospheric carbon tetrachloride $\left(\mathrm{CCl}_{4}\right)$ to the ocean, Atmos. Chem. Phys., 16, 10899-10910, doi:10.5194/acp-1610899-2016, 2016.

Carpenter, L. J., Reimann, S., Burkholder, J. B., Clerbaux, C., Hall, B. D., Hossaini, R., Laube, J. C., and Yvon-Lewis, S. A.: OzoneDepleting Substances (ODSs) and Other Gases of Interest to the Montreal Protocol, chap. 1 in Scientific Assessment of Ozone Depletion: 2014, Global Ozone Research and Monitoring Project - Report No. 55, World Meteorological Organization, Geneva, Switzerland, 2014.

Contributors AGAGE science team: The ALE/GAGE/AGAGE Network (DB1001), Advanced Global Atmospheric Gases Experiment Science Team, http://cdiac.esd.ornl.gov/ndps/alegage.html, last access: 1 May 2016.

Eckhardt, S., Prata, A. J., Seibert, P., Stebel, K., and Stohl, A.: Estimation of the vertical profile of sulfur dioxide injection into the atmosphere by a volcanic eruption using satellite column measurements and inverse transport modeling, Atmos. Chem. Phys., 8, 3881-3897, doi:10.5194/acp-8-3881-2008, 2008.

Fraser, P., Gunson, M., Penkett, S., Rowland, F. S., Schmidt, U., and Weiss, R.: Report on concentrations, lifetimes, and trends of CFCs, halons, and related species, NASA Ref. Publ., 1339, 1.11.68, 1994.

Fraser, P., Dunse, B., Manning, A. J., Wang, R., Krummel, P., Steele, P., Porter, L., Allison, C., O'Doherty, S., Simmonds, P., Mühle, J., and Prinn, R.: Australian carbon tetrachloride $\left(\mathrm{CCl}_{4}\right)$ emissions in a global context, Environ. Chem., 11, 77-88, 2014.

Galbally, I. E.: Man-Made Carbon Tetrachloride in the Atmosphere, Science, 193, 573-576, doi:10.1126/science.193.4253.573, 1976.

Giostra, U., Furlani, F., Arduini, J., Cava, D., Manning, A. J., O'Doherty, S. J., Reimann, S., and Maione, M.: The determination of a regional atmospheric background mixing ratio for anthropogenic greenhouse gases: a comparison of two independent methods, Atmos. Environ., 45, 7396-7405, 2011.

Graziosi, F., Arduini, J., Furlani, F., Giostra, U., Kuijpers, L. J. M., Montzka, S. A., Miller, B. R., O’Doherty, S. J., Stohl, A., Bonasoni, P., and Maione, M.: European emissions of HCFC-22 based on eleven years of high frequency atmospheric measurements and a Bayesian inversion method, Atmos. Environ., 112, 196207, doi:10.1016/j.atmosenv.2015.04.042, 2015.
Happell, J. D., Mendoza, Y., and Goodwin, K.: A reassessment of the soil sink for atmospheric carbon tetrachloride based upon static flux chamber measurements, J. Atmos. Chem., 71, 113123, 2014.

Harris, N. R. P., Wuebbles, D. J., Daniel, J. S., Hu, J., Kuijpers, L. J. M., Law, K. S., Prather, M. J., and Schofield, R.: Scenarios and Information for Policymakers, chap. 5 in Scientific Assessment of Ozone Depletion: 2014, Global Ozone Research and Monitoring Project-Report No. 55. World Meteorological Organization, Geneva, Switzerland, 2014.

Hu, L., Montzka, S. A., Miller, B. R., Andrews, A. E., Miller, J. B., Lehman, S. J., Sweeney, C., Miller, S., Thoning, K., Siso, C., Atlas, E., Blake, D., de Gouw, J. A., Gilman, J. B., Dutton, G. J., Elkins, J. W., Hall, B. D., Chen, H., Fischer, M. L., Mountain, M., Nehrkorn, T., Biraud, S. C., Moore, F., and Tans, P. P.: Continued emissions of carbon tetrachloride from the U.S. nearly two decades after its phase-out for dispersive uses, P. Natl. Acad. Sci. USA, 113, 2880-2885, 2016.

Laube, J. C., Keil, A., Bönisch, H., Engel, A., Röckmann, T., Volk, C. M., and Sturges, W. T.: Observation-based assessment of stratospheric fractional release, lifetimes, and ozone depletion potentials of ten important source gases, Atmos. Chem. Phys., 13, 2779-2791, doi:10.5194/acp-13-2779-2013, 2013.

Liang, Q., Newman, P. A., Daniel, J. S., Reimann, S., Hall, B. D., Dutton, G., and Kuijpers, L. J. M.: Constraining the carbon tetrachloride $\left(\mathrm{CCl}_{4}\right)$ budget using its global trend and inter-hemispheric gradient, Geophys. Res. Lett., 41, 5307-5315, doi:10.1002/2014GL060754, 2014.

Lunt, M. F., Rigby, M., Ganesan, A. L., Manning, A. J., Prinn, R. G., O’Doherty, S., Muhle, J., Harth, C. M., Salameh, P. K., Arnold, T., Weiss, R. F., Saito, T., Yokouchi, Y., Krummel, P. B., Steele, L., Fraser, P. J., Li, S., Park, S., Reimann, S., Vollmer, M. K., Lunder, C., Hermansen, O., Schmidbauer, N., Maione, M., Arduini, J., Young, D., and Simmonds, P. G.: Reconciling reported and unreported HFC emissions with atmospheric observations, P. Natl. Acad. Sci. USA, 112, 5927-5931 doi:doi:10.1073/pnas.1420247112, 2015.

Maione, M., Giostra, U., Arduini, J., Furlani, F., Graziosi, F., Lo Vullo, E., and Bonasoni, P.: Ten years of continuous observations of stratospheric ozone depleting gases at Monte Cimone (Italy) - Comments on the effectiveness of the Montreal Protocol from a regional perspective, Sci. Total Environ., 445-446, 155-164, 2013.

Maione, M., Graziosi, F., Arduini, J., Furlani, F., Giostra, U., Blake, D. R., Bonasoni, P., Fang, X., Montzka, S. A., O’Doherty, S. J., Reimann, S., Stohl, A., and Vollmer, M. K.: Estimates of European emissions of methyl chloroform using a Bayesian inversion method, Atmos. Chem. Phys., 14, 9755-9770, doi:10.5194/acp14-9755-2014, 2014.

Manning, A. J., O’Doherty, S., Jones, A. R., Simmonds, P. G., and Derwent, R. G.: Estimating UK methane and nitrous oxide emissions from 1990 to 2007 using an inversion modelling approach, J. Geophys. Res., 116, D02305, doi:10.1029/2010JD014763, 2011.

Miller, B. R., Weiss, R. F., Salameh, P. K., Tanhua, T., Greally, B. R., Mühle, J., and Simmonds, P. G.: Medusa: A sample preconcentration and GC/MS detector system for in situ measurements of atmospheric trace halocarbons, hydrocarbons, and sulphur compounds, Anal. Chem., 80, 1536-1545, 2008. 
Miller, J. B., Lehman, S. J., Montzka, S. A., Sweeney, C., Miller, B. R., Karion, A., Wolak, C., Dlugokencky, E. J., Southon, J., Turnbull, J. C., and Tans, P. P.: Linking emissions of fossil fuel $\mathrm{CO}_{2}$ and other anthropogenic trace gases using atmospheric $14 \mathrm{CO}_{2}$, J. Geophys. Res., 117, D08302, doi:10.1029/2011JD017048, 2012.

Montzka, S. A., Reimann, S., Engel, A., Krüger, K., O’Doherty, S., Sturges, W. T., Blake, D. R., Dorf, M., Fraser, P. J., Froidevaux, L., Jucks, K., Kreher, K., Kurylo, M. J., Mellouki, A., Miller, J., Nielsen, O.-J., Orkin, V. L., Prinn, R. G., Rhew, R., Santee, M. L., and Verdonik, D. P.: Ozone-Depleting Substances (ODSs) and related chemicals, chap. 1 in Scientific Assessment of Ozone Depletion: 2010, Global Ozone Research and Monitoring Project - Report No. 52, World Meteorogical Organization, Geneva, Switzerland, 2011.

Myhre, G., Shindell, D., Bréon, F.-M., Collins, W., Fuglestvedt, J., Huang, J., Koch, D., Lamarque, J.-F., Lee, D., Mendoza, B., Nakajima, T., Robock, A., Stephens, G., Takemura, T., and Zhang, H.: Anthropogenic and Natural Radiative Forcing, in: Climate Change 2013: The Physical Science Basis. Contribution of Working Group I to the Fifth Assessment Report of the Intergovernmental Panel on Climate Change, edited by: Stocker, T. F., Qin, D., Plattner, G.-K., Tignor, M., Allen, S. K., Boschung, J., Nauels, A., Xia, Y., Bex, V., and Midgley, P. M., Cambridge University Press, Cambridge, UK and New York, NY, USA, 2013.

Nisbet, E. and Weiss, R.: Top-Down Versus Bottom-Up, Science, 328, 1241-1243, doi:10.1126/science.1189936, 2010.

Odabasi, M., Elbir, T., Dumanoglu, Y., and Sofuoglu, S. C.: Halogenated volatile organic compounds in chlorine-bleachcontaining household products and implications for their use, Atmos. Environ. 92, 376-383, 2014.

Prinn, R. G., Weiss, R. F., Fraser, P. J., Simmonds, P. G., Cunnold, D. M., Alyea, F. N., O’Doherty, S., Salameh, P., Miller, B. R., Huang, J., Wang, R. H. J., Hartley, D. E., Harth, C., Steele, L. P., Sturrock, G., Midgley, P. M., and McCulloch, A.: A history of chemically and radiatively important gases in air deduced from ALE/GAGE/AGAGE, J. Geophys. Res., 105, 1775117792, 2000.

Seibert, P.: Inverse modelling of sulphur emissions in Europe based on trajectories, in: Inverse Methods in Global Biogeochemical Cycles, edited by: Kasibhatla, P., Heimann, M., Rayner, P., Mahowald, N., Prinn, R. G., and Hartley, D. E., Geophysical Monograph, Munich, 114, 147-154, American Geophysical Union, 2000.

Seibert, P.: Inverse modelling with a Lagrangian particle dispersion model: application to point releases over limited time intervals, in: Air Pollution Modelling and its Application XIV, edited by: Schiermeier, F. A. and Gryning, S.-E., Kluwer Academic Publ., New York, USA, 381-389, 2001.

Simmonds, P. G., Cunnold, D. M., Weiss, R. F., Prinn, R. G., Fraser, P. J., McCulloch, A., Alyea, F. N., and O'Doherty, S.: Global trends and emissions estimates of $\mathrm{CCl}_{4}$ from in-situ background observations from July 1978 to June 1996, J. Geophys. Res., 103, 16017-16027, 1998 .

Simmonds, P. G., O’Doherty, S., Derwent, R. G., Manning, A. J., Ryall, D. B., Fraser, P., Porter, L., Krummel, P., Weiss, R., Miller, B., Salameh, P., Cunnold, D., Wang, R., and Prinn, R.: AGAGE observations of methyl bromide and methyl chloride at the Mace
Head, Ireland and Cape Grim, Tasmania, 1998-2001, J. Atmos. Chem., 47, 243-269, 2004.

SPARC: SPARC Report on the Lifetimes of Stratospheric OzoneDepleting Substances, Their Replacements, and Related Species, edited by: Ko, M., Newman, P., Reimann, S., and Strahan, S., SPARC Report No. 6, WCRP-15/2013, available at: http://www. sparc-climate.org/publications/sparc-reports/sparc-report-no6/ (last access: 1 May 2016), 2013.

Stohl, A., Forster, C., Frank, A., Seibert, P., and Wotawa, G.: Technical note: The Lagrangian particle dispersion model FLEXPART version 6.2, Atmos. Chem. Phys., 5, 2461-2474, doi:10.5194/acp-5-2461-2005, 2005.

Stohl, A., Seibert, P., Arduini, J., Eckhardt, S., Fraser, P., Greally, B. R., Lunder, C., Maione, M., Mühle, J., O’Doherty, S., Prinn, R. G., Reimann, S., Saito, T., Schmidbauer, N., Simmonds, P. G., Vollmer, M. K., Weiss, R. F., and Yokouchi, Y.: An analytical inversion method for determining regional and global emissions of greenhouse gases: Sensitivity studies and application to halocarbons, Atmos. Chem. Phys., 9, 1597-1620, doi:10.5194/acp-91597-2009, 2009.

Stohl, A., Kim, J., Li, S., O’Doherty, S., Mühle, J., Salameh, P. K., Saito, T., Vollmer, M. K., Wan, D., Weiss, R. F., Yao, B., Yokouchi, Y., and Zhou, L. X.: Hydrochlorofluorocarbon and hydrofluorocarbon emissions in East Asia determined by inverse modeling, Atmos. Chem. Phys., 10, 35453560, doi:10.5194/acp-10-3545-2010, 2010.

Sturrock, G. A., Etheridge, D. M., Trudinger, C. M., Fraser P. J., and Smith A. M.: Atmospheric histories of halocarbons from analysis of Antarctic firn air: Major Montreal Protocol species, J. Geophys. Res., 107, 4765, doi:10.1029/2002JD002548, 2002.

UNEP: Report on Emissions Reductions and Phase-Out of CTC (Decision 55/ 45), UNEP/OzL.Pro/ExCom/58/50, United Nations Environment Programme, Executive Committee of the Multilateral Fund for the Implementation of the Montreal Protocol: Montreal, Canada, 2009.

UNEP: Report of the UNEP Technology and Economic Assessment Panel: May 2013 Progress Report, Vol. 1, edited by: Kuijpers, L. and Seki, M., United Nations Environment Programme, Nairobi, Kenya, availalbe at: http://ozone.unep.org/Assessment_Panels/TEAP/Reports/ TEAP_Reports/TEAP_Progress_Report_May_2013.pdf (last access: 1 May 2016), 2013.

Vollmer, M. K., Zhou, L. X., Greally, B. R., Henne, S., Yao, B., Reimann, S., Stordal, F., Cunnold, D. M., Zhang, X. C., Maione, M., Zhang, F., Huang, J., and Simmonds, P. G.: Emissions of ozone-depleting halocarbons from China, Geophys. Res. Lett., 36, L15823, doi:10.1029/2009GL038659, 2009.

Walker, S. J., Weiss, R. F., and Salameh P. K.: Reconstructed histories of the annual mean atmospheric mole fractions for the halocarbons CFC-11, CFC-12, CFC-113, and carbon tetrachloride, J. Geophys. Res., 105, 14285-14296, 2000.

Weiss, R. F. and Prinn, R. G.: Quantifying greenhouse-gas emissions from atmospheric measurements: a critical reality check for climate legislation, Philos. T. Roy. Soc. A, 369, 1925-1942, doi:10.1098/rsta.2011.0006, 2011.

Xiao, X., Prinn, R. G., Fraser, P. J., Weiss, R. F., Simmonds, P. G., O’Doherty, S., Miller, B. R., Salameh, P. K., Harth, C. M., Krummel, P. B., Golombek, A., Porter, L. W., Butler, J. H., Elkins, J. W., Dutton, G. S., Hall, B. D., Steele, L. P., Wang, R. H. J., and 
Cunnold, D. M.: Atmospheric three-dimensional inverse modeling of regional industrial emissions and global oceanic uptake of carbon tetrachloride, Atmos. Chem. Phys., 10, 10421-10434, doi:10.5194/acp-10-10421-2010, 2010.
Yvon-Lewis, S. A. and Butler J. H.: Effect of oceanic uptake on atmospheric lifetimes of selected trace gases, J. Geophys. Res., 107, 4414, doi:10.1029/2001JD001267, 2002. 